\author{
B. LUKIĆ ${ }^{1}$ \\ J.W. SEO ${ }^{1}$ \\ E. COUTEAU ${ }^{1}$ \\ K. LEE $^{1}$ \\ S. GRADEČAK ${ }^{2}$ \\ R. BERKECZ ${ }^{3}$ \\ K. HERNADI ${ }^{3}$ \\ S. DELPEUX ${ }^{4}$ \\ T. CACCIAGUERRA ${ }^{4}$ \\ F. BÉGUIN ${ }^{4}$ \\ A. FONSECA ${ }^{5}$ \\ J.B. NAGY ${ }^{5}$ \\ G. CSÁNYI ${ }^{6}$ \\ A. $\mathrm{KIS}^{1}$ \\ A.J. KULIK ${ }^{1}$ \\ L. FORRÓ ${ }^{1, \infty}$
}

\section{Elastic modulus \\ of multi-walled carbon nanotubes produced by catalytic chemical vapour deposition}

\footnotetext{
${ }^{1}$ Institut de la Physique de la Matière Complexe, Ecole Polytechnique Fédérale de Lausanne, 1015 Lausanne, Switzerland

${ }^{2}$ Centre Interdisciplinaire de Microscopie Electronique,

Ecole Polytechnique Fédérale de Lausanne, 1015 Lausanne, Switzerland

${ }^{3}$ Department of Applied and Environmental Chemistry, University of Szeged, Rerrich Béla tér 1, 6720 Szeged, Hungary

${ }^{4}$ CRMD, CNRS-Université, 1B rue de la Férollerie, 45071 Orléans Cedex 02, France

${ }^{5}$ Facultés Universitaires Notre-Dame de la Paix, 61 rue de Bruxelles, 5000 Namur, Belgium

${ }^{6}$ TCM Group, Cavendish Laboratory, University of Cambridge, Madingley Road,

Cambridge CB3 OHE, UK
}

Received: 7 June 2004/Accepted: 19 October 2004

Published online: 15 December 2004 • () Springer-Verlag 2004

ABSTRACT Carbon nanotubes (CNTs) are ideal structures for use as reinforcement fibres in composite materials, due to their extraordinary mechanical properties, in particular high Young's modulus $(E \sim 1 \mathrm{TPa})$. Usually the high value of $E$ is taken as granted for all types of carbon CNTs. Here we demonstrate that multi-walled carbon nanotubes (MWCNTs) produced by catalytic chemical vapour deposition (CCVD) have low moduli $(E<100 \mathrm{GPa})$ independently of their growth conditions. We attribute this to the presence of structural defects. Additional high-temperature annealing failed to improve the mechanical properties. This study urges a better control of the growth process in order to obtain high strength CCVD grown MWCNTs suitable for reinforcement in large-scale industrial applications.

PACS 62.25.+g; 68.37.Ps; 81.15.Gh

1

\section{Introduction}

Carbon nanotubes [1] (CNTs) are of interest both from a fundamental point of view and for future applications. Apart from their remarkable electronic and thermal properties [2,3], they also show unique mechanical characteristics with high Young's modulus $(\sim 1 \mathrm{TPa})$ and breaking strength combined with low density [4-10]. As such, they are ideal candidates as reinforcement fibres in composite materials. The method of catalytic chemical vapour deposition (CCVD) [11] is the most promising in terms of large-scale production due to the possibility to upscale both production and purification methods [12]. This process involves high-temperature $\left(600^{\circ} \mathrm{C}\right.$ to $\left.1200^{\circ} \mathrm{C}\right)$ catalytic decomposition of hydrocarbons on metallic catalyst particles. The common view holds that CNTs grow by the extrusion of carbon dissolved in a catalyst particle that is oversaturated in carbon at one part of the surface [13]. Production is usually chosen to give a high yield of CNTs of a specific type, while the value of Young's modulus is assumed to be $\sim 1 \mathrm{TPa}$, the same as for multi-walled and single-walled carbon nanotubes (MWCNTs and SWCNTs) grown by arc discharge and laser ablation, respectively $[5,10]$. But, the very first study of Salvetat etal. [7] has shown that CCVD-grown CNTs have poor mechanical properties with Young's modulus in the range of 10 to $50 \mathrm{GPa}$ [7] due to the misalignment of graphitic planes and the tube axis.
Here we report a systematic study of the elastic measurements of CCVDgrown MWCNTs produced under various growth conditions. The observed wall structure is significantly better than in the previous study - no misalignment and better graphitization but all MWCNTs show Young's modulus lower than $100 \mathrm{GPa}$. An attempt to improve their structure by hightemperature annealing failed to improve their elastic property. This study suggests that MWCNTs produced by the CCVD method have a large number of defects, which are difficult to recuperate from afterwards. There is clearly a need to optimize the growth conditions in order to produce high strength CCVD grown CNTs.

\section{Experimental \\ $2.1 \quad C C V D$ production and high-temperature annealing of MWCNTs}

Four batches of MWCNTs were prepared by the CCVD method in different laboratories. All used acetylene as the carbon source. The main variation was in the choice of support material for catalytic particles, which can influence strongly the CNTs' characteristics [14].

Here we give a short description with details given as noted: batch I. MWCNTs were produced by catalytic decomposition of acetylene on $\mathrm{Co} / \mathrm{NaY}$ zeolite catalyst in the temperature range 
700-800 ${ }^{\circ} \mathrm{C}$ [15]; batch II. MWCNTs were produced by catalytic decomposition of acetylene at $600{ }^{\circ} \mathrm{C}$ on a $\operatorname{Cox} \mathrm{Mg}(1-\mathrm{x}) \mathrm{O}$ solid solution containing 40 wt. $\%$ of $\mathrm{CoO}$. Silica was used as a support $[16,17]$; batch III. $\mathrm{Li}_{2} \mathrm{CO}_{3}$ supported $\mathrm{Fe} / \mathrm{Co}$ catalysts were prepared from acetone and acetylene was decomposed at $700^{\circ} \mathrm{C}$; batch IV. Acetylene was decomposed on $\mathrm{Co}-\mathrm{Fe}$ particles on a $\mathrm{CaCO}_{3}$ support $(5 \mathrm{wt} . \%$ of $\mathrm{Co}, \mathrm{Fe})$ at $720^{\circ} \mathrm{C}[18]$.

MWCNTs from batch II were annealed at temperatures of $1200^{\circ} \mathrm{C}$, $1700^{\circ} \mathrm{C}, 2100^{\circ} \mathrm{C}$ and $2400^{\circ} \mathrm{C}$. Annealing was realized in a graphitization furnace under an argon flow of $31 / \mathrm{min}$; the heating rate was $13{ }^{\circ} \mathrm{C} / \mathrm{min}$ with $15 \mathrm{~min}$ of resident time at the desired temperature.

\section{2}

\section{Structural and mechanical characterization}

Transmission electron microscopy (TEM) characterization was carried out using a Philips CM300 FEG microscope operating at $300 \mathrm{kV}$. For TEM sample preparation, CNTs were dispersed in isopropanol and sonicated for $5 \mathrm{~min}$. A droplet of suspension was put on a $\mathrm{Cu}$ TEM grid with a holey $\mathrm{C}$ film.

For atomic force microscopy (AFM) measurements, MWCNTs were dispersed in ethanol by sonication for 5 to 10 min and a droplet of suspension was placed over a polished alumina membrane (Whatman Anodisc, nominal pore diameter of $200 \mathrm{~nm}$ ) itself placed on filter paper and then filtrated for a few minutes. Measurements for some tubes from batch II and for all tubes from batch III were made on $\mathrm{Si}_{3} \mathrm{~N}_{4}$ microfabricated membranes with arrays of holes $1 \mu \mathrm{m}$ in diameter. AFM images were taken in contact mode operating in air (Autoprobe CP or Autoprobe M5, Park Scientific Instruments), varying the load from image to image. Sharpened noncoated or gold-coated $\mathrm{Si}_{3} \mathrm{~N}_{4}$ cantilevers (ThermoMicroscopes) with force constant $0.01-0.1 \mathrm{~N} \mathrm{~m}^{-1}$ were used. The force constant was calibrated prior to the measurement [19].

\section{Results and discussion \\ 3.1 Structure studied by transmission electron microscopy (TEM)}

Figure 1 displays characteristic low-magnification TEM images of the CCVD-grown nanotubes of batches I, III and IV, while for batch II they can be found elsewhere [20]. CNTs from all batches are preferentially curved on the length scale of several hundred nanometres, except for batch III where MWCNTs are straight on a micron scale. This demonstrates the importance of the choice of the support, which is the principal difference in preparation between batches III and IV. Graphitic sheets aligned parallel to the tube axis can be seen in the high-resolution TEM images of Fig. 2. The wall structure of these tubes is very similar to the wall structure of MWCNTs grown by the arc-discharge method. MWCNTs vary in outer diameter within one batch as estimated by TEM. Those from batch I have diameters in the range of 20 to $30 \mathrm{~nm}$ [15], batch II have 10 to $15 \mathrm{~nm}$, with an inner diameter between 3 and $4 \mathrm{~nm}$ [16], while MWCNTs from batch IV show somewhat bigger variation from 30 to $80 \mathrm{~nm}$ for the outer diameter. MWCNTs from batch III have an outerdiameter distribution of $58 \pm 12 \mathrm{~nm}$ and an exceptionally large inner diameter that can reach $35 \mathrm{~nm}$ (Fig. 2b).

\section{2}

\section{Mechanical properties studied by atomic force microscopy (AFM)}

When imaged by AFM, we could observe rings of MWCNTs on the alumina surface in the case of batch I, as can be seen in Fig. 3a. They are most likely formed by the surface tension of the air bubbles generated by the sonication of the ethanol/nanotube suspension. After placement of a droplet of the suspension on the substrate and subsequent evaporation of the solvent, the nanotube ring is stabilized by van der Waals interaction on the surface $[21,22]$. This observation already suggests a weak mechanical strength of the CCVDgrown MWCNTs, since coiling involves significant strain energy due to the increased curvature.

One method for measuring the elastic modulus of a CNT is to clamp the nanotube at each end and to measure its vertical deflection versus the force applied at a point midway along its length. Here, we measured Young's modulus $E$ by AFM using a method described previously [23]. After sample preparation, nanotubes occasionally lie over a hole with a short section of their entire length, whereas the major part of the nanotube is still in contact with
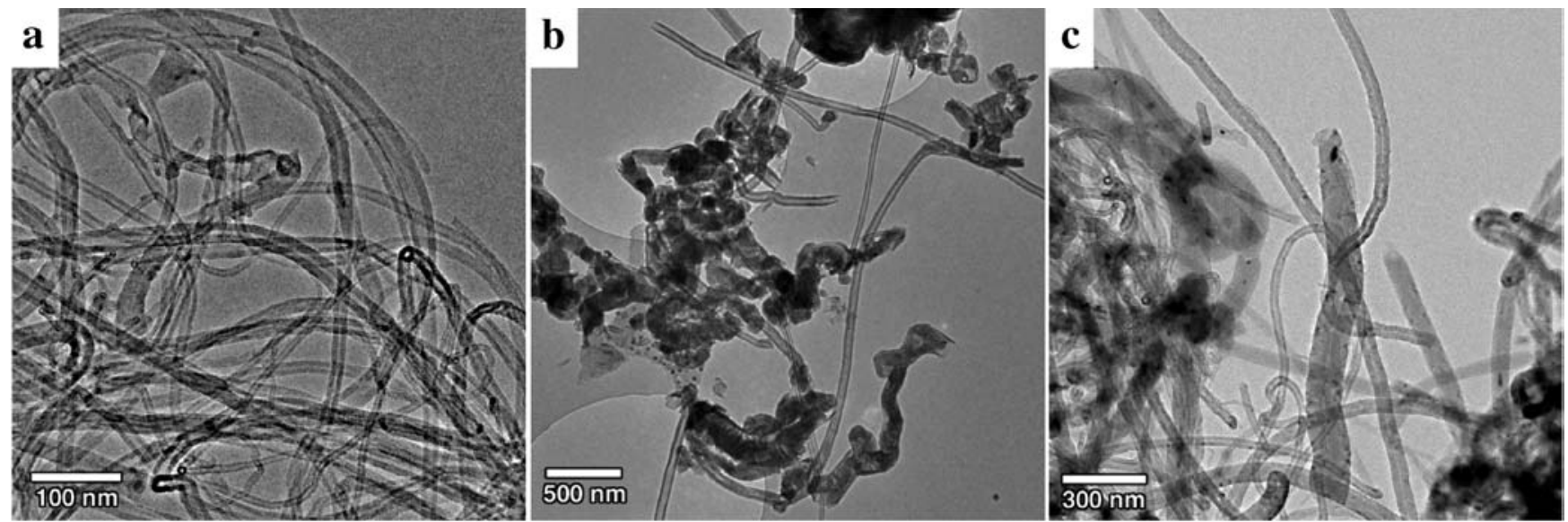

FIGURE 1 Characteristic low-resolution TEM images of CCVD-grown CNTs from a batch I, $\mathbf{b}$ batch III, $\mathbf{c}$ batch IV. Scales are different due to differences in the size of MWCNTs 

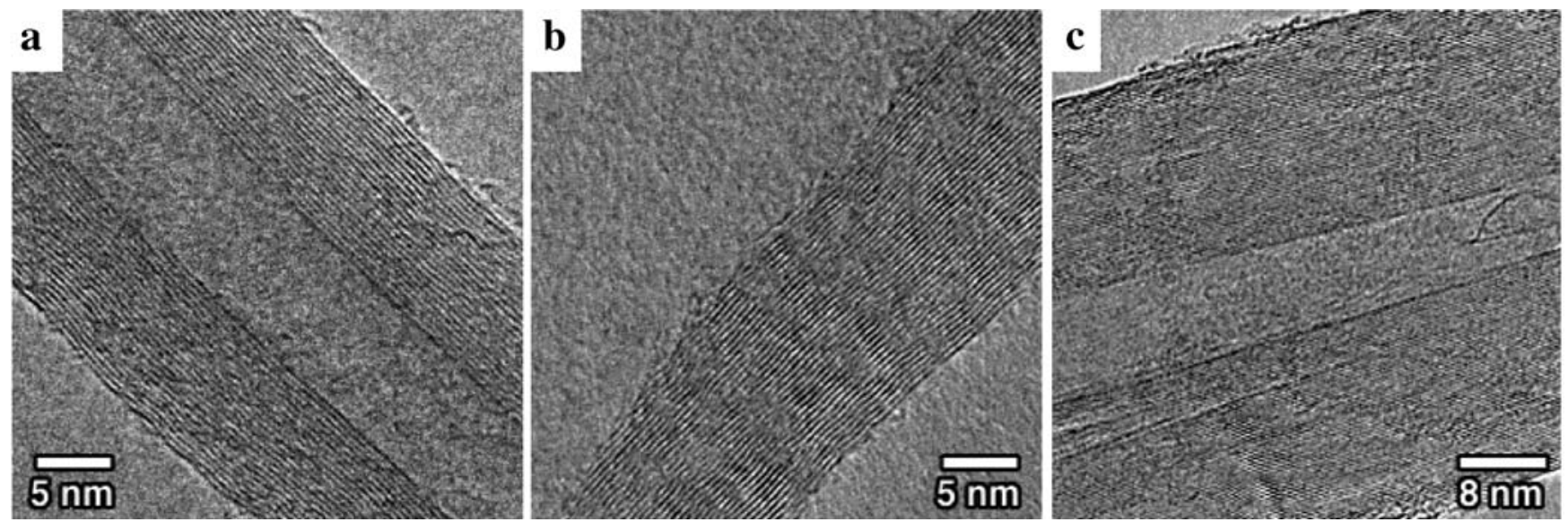

FIGURE 2 Characteristic high-resolution TEM images with the same marks as in Fig. 1. Scales are different due to differences in the diameter of MWCNTs. Only one side for MWCNTs from batch III (b) is shown since the inner channel is too big $(\sim 35 \mathrm{~nm})$. The inner channel is on the top

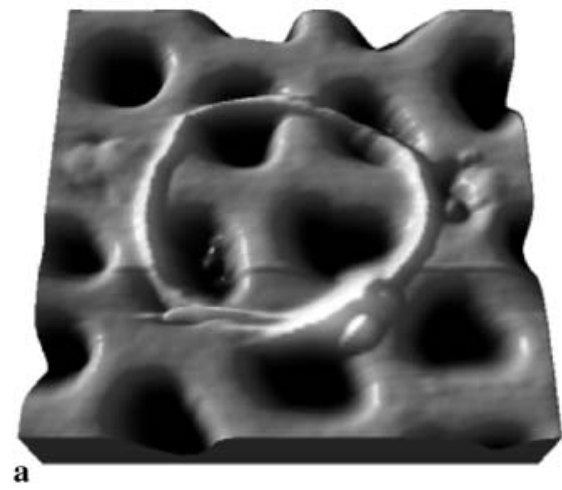

FIGURE 3 (a) Three-dimensional rendering of an AFM image showing MWCNT ring structure (batch I) deposited on the alumina membrane after solvent evaporation (image area $\sim 1 \mu \mathrm{m}^{2}$ ). (b) Deflection versus applied force for a MWCNT measured by AFM. The deflection is measured on the suspended portion of the nanotube over the hole on which the AFM cantilever applies the force. For forces up to $10 \mathrm{nN}$, the response to deflection is linear. The line is a linear regression fit of experimental data, and its inverse value $F / \delta$ is used to calculate Young's modulus

the membrane surface. During scanning with the AFM tip, the suspended nanotube bends and the vertical deflection in the middle $\delta$ can be directly deduced from an AFM image (Fig. 3b). The height of the nanotube was derived from a part that lies on the flat membrane surface and was set equal to the diameter $D$. This estimate is more precise than the measured width due to the tip-convolution effect. For the suspended length $L$ we take the pore width on sites just next to the nanotube. Due to irregular pore shape, the error in $L$ is about $10 \%$. Using simple beam mechanics [24], the Young's modulus $E$ is estimated from $E=F L^{3} / \delta \alpha I$, where $\alpha=192$ for a clamped beam, $F$ is the applied force varying from image to image and $I=\pi\left(D^{4}-D_{\mathrm{i}}^{4}\right) / 64, D_{\mathrm{i}}$ being the inner radius of a MWCNT. By neglecting $D_{\mathrm{i}}(<5 \mathrm{~nm})$ we underesti-

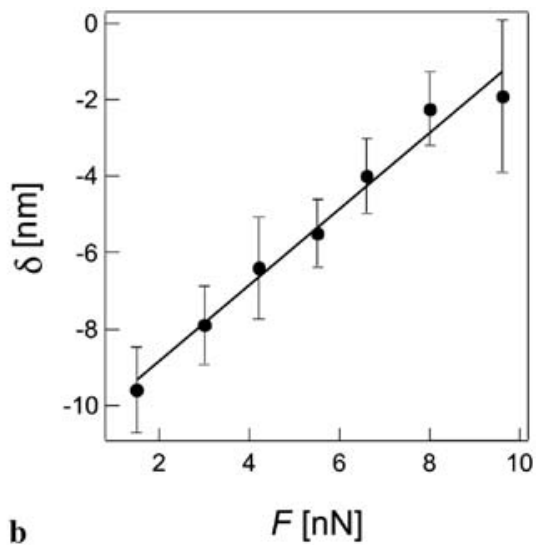

mate the values for $E$, but that error is still small compared to the error made by the determination of $L$, which contributes most to the error in $E$. Even for the case of MWCNTs from batch III, which have large $D_{\mathrm{i}}$, underestimation can reach $\sim 20 \%$.

Calculation of $E$ is based on the assumption of the nanotube being perfectly clamped to the alumina membrane. Adhesion depends on the real contact surface between the nanotube and the substrate, and if the contact surface is small (either due to the bent structure or an inhomogeneous surface) the nanotubes move. MWCNTs deposited on $\mathrm{SiO}_{2}$ surface can be moved with an AFM tip with normal forces of 10-50 nN [25], and we observed several such events in our samples, but with forces below $10 \mathrm{nN}$. However, none of the nanotubes presented above moved from one AFM image to another, that is to say, each point in the force-deflection curve was measured for the same nanotube position over the hole. The investigated force range reached maximally $11 \mathrm{nN}$.

A summary of mechanical measurements is shown in Fig. 4. For the sake of comparison, results of the Young's moduli of MWCNTs grown by arc discharge from previous work [7] are included. Average values of $E$ for each batch of MWCNTs are grouped in three bins per decade so that the bins have equal range on a logarithmic scale. Such a representation is used to capture data that span several orders of magnitude. Values for batches I and II follow a Gaussian-like distribution, while other batches probably follow the same pattern, although this cannot be readily established due to the smaller number of data points. Nevertheless, CCVD-grown MWCNTs evidently have a low Young's modulus for all four batches, with a distribution of values in the range between $1 \mathrm{GPa}$ and $100 \mathrm{GPa}$.

\subsection{Origin of low Young's modulus}

Our results are in agreement with the values reported in the first study of CCVD-grown MWCNTs, but it has to be noted that in that study only five MWCNTs from one batch were measured [7]. Such low values were explained by misalignment of the graphitic planes with the tube axis, where planes and axis enclosed an angle $\varphi=30^{\circ} \mathrm{C}$. As a rough approximation, the measurement can be considered as the Young's modulus of a single graph- 
- CCVD Batch I I CCVD Batch III

a CCVD Batch II $\quad$ a CCVD Batch IV

$\square$ Arc-discharge grown MWCNTs

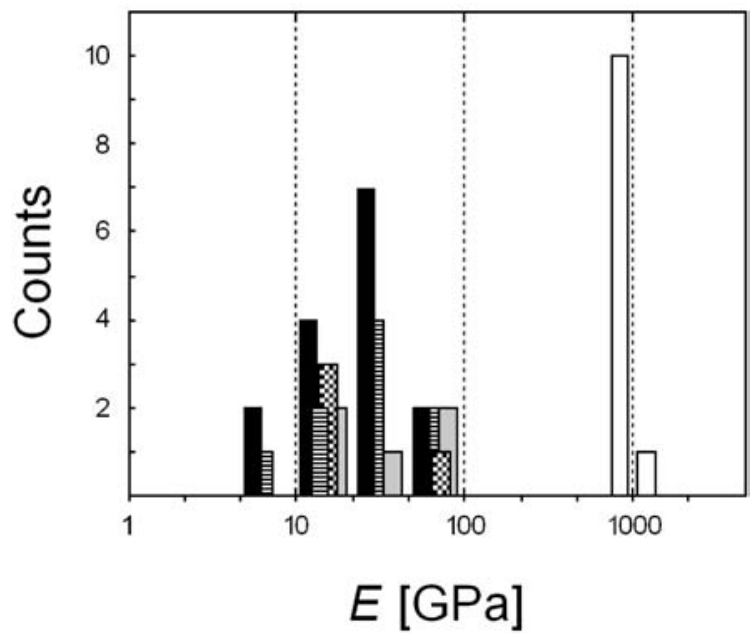

FIGURE 4 Histogram of average values of Young's modulus $E$ for batches I to IV. There are three bins per decade presented in a way to make the range of the bins equal on logarithmic scales. Values for arc-dischargegrown MWCNTs [7] are shown separately ('arc-discharge grown MWCNTs')

ite crystal measured in the direction that includes an angle of $\varphi$ with the hexagonal axis. Variation of the elastic modulus with $\varphi$ is then given by $1 / E=S_{11}\left(1-\gamma^{2}\right)^{2}+S_{33} \gamma^{4}+\left(2 S_{13}+\right.$ $\left.S_{44}\right) \gamma^{2}\left(1-\gamma^{2}\right)$, where $S_{i j}$ are elastic compliances of bulk graphite and $\gamma=$ $\sin (\varphi)$ [26]. As can be seen in Fig. 2, the MWCNTs in this study showed better structure in general: batch III MWCNTs reveal $\varphi \sim 10^{\circ} \mathrm{C}$, which gives $E \sim 150 \mathrm{GPa}$; MWCNTs from batches I and IV have $\varphi \sim 0{ }^{\circ} \mathrm{C}$, which gives $E=1 / S_{11} \sim 1000 \mathrm{GPa}$ [26]. This calculation shows that misalignment alone cannot explain the obtained low values of Young's modulus, and their origin must lie elsewhere.

It is rather difficult to determine the presence of structural defects and their distribution in the structure of MWCNTs. TEM can determine misalignment of graphitic sheets or poor graphitization, but not other defects like vacancies, interstitials of carbon or atoms of the catalyst, carboxyl groups that are attached to the walls during purification, or edge dislocations. Point defects inside planes, like vacancies and interstitials, should not significantly influence mechanical properties, unless their density is increased sufficiently.

In order to estimate to what extent vacancies reduce the Young's modulus of CNTs, we performed theoretical calculations. We used ab initio plane wave density functional theory [27] in the GGA approximation [28] (as implemented in the CASTEP code [29]).
All calculations were done on the $(5,5)$ armchair tube, using a 100-atom unit cell, $8 \mathrm{~K}$ points along the tube axis, 336-eV plane-wave cut-off and ultrasoft pseudopotentials. For each structure all coordinates were optimized. To get the Young's modulus, the unit cell was stretched slightly and the internal coordinates were re-optimized. The pristine tube was found to have a modulus of $0.85 \mathrm{TPa}$. Both a single vacancy and a divacancy oriented perpendicular to the tube axis reduced this to around $0.75 \mathrm{TPa}$. The main uncertainty in the absolute (but not the relative) magnitudes of these results is due to the translation of the energy of stretching in units of pressure, which was done using a SWCNT bundle with a triangular lattice constant of $10 \AA$. Another study performed on a larger SWCNT showed an even smaller effect: removal of $4.7 \%$ of the SWCNT's surface decreases bending rigidity by only $24 \%$ [30]. In conclusion, vacancies cannot explain the order of magnitude decrease of $E$ from the optimal value of $1 \mathrm{TPa}$.

Non-planar defects could influence mechanical properties in a more significant way. Intuitively, when Young's modulus is estimated from elongation due to the tensile strength, edge dislocations parallel to the tube axis will not influence it. In contrast, when estimated from bending rigidity, as in our experiment, the effect of the dislocations should be more profound. Unfortunately, simulations show that they are difficult to observe with TEM when they are projected normal to the tube axis (which is the most often used viewing direction) [31].

\subsection{High-temperature annealing of MWCNTs}

In the case of micrometresized carbon tubes, the annealing at temperatures from 1600 to $2400{ }^{\circ} \mathrm{C}$ changed the structure from disordered amorphous carbon to a more ordered and preferentially oriented graphitic phase, as studied by TEM, Raman spectroscopy and X-ray powder diffraction [32]. Several other TEM and thermogravimetric studies $[20,33,34]$ have suggested the same positive effect of annealing on the CCVD-grown MWCNTs.

We have employed this strategy to improve mechanical properties of MWCNTs from batch II. Lack of graphitization or disordered graphitic layers are reasons for low values in this batch, which is not surprising since they are made using a similar production technique and conditions as in the previous study [7]. Exposing MWCNTs to a higher temperature might eliminate at least partly the defects that are present in the wall structure after the production. Since energies in the order of $\mathrm{eV}$ are required for migration of vacancies [35] and interstitials [36], temperatures around $2000{ }^{\circ} \mathrm{C}$ increase the migration probability by several orders of magnitude and may consequently lead to their recombination and subsequent annihilation in the structure. High-resolution TEM studies of MWCNTs irradiated by a large flux of electrons show possible pathways for improvements in the wall structure when there is sufficient energy: fusion of the round-shaped graphene into the walls or rearrangement of the graphene layers [37].

Annealing was performed on MWCNTs from batch II in argon atmosphere at temperatures of $1200{ }^{\circ} \mathrm{C}, 1700^{\circ} \mathrm{C}$, $2100^{\circ} \mathrm{C}$ and $2400^{\circ} \mathrm{C}$. Representative TEM images of MWCNTs annealed at selected temperatures (TEM images of pristine MWCNTs can be found elsewhere [20]) are shown in Fig. 5a. The wall structure seems to improve with higher-temperature treatments, but this is not reflected in the values of Young's modulus shown in Fig. 5b. All the measurements for annealed tubes at different temperatures show that $E$ does not reach 

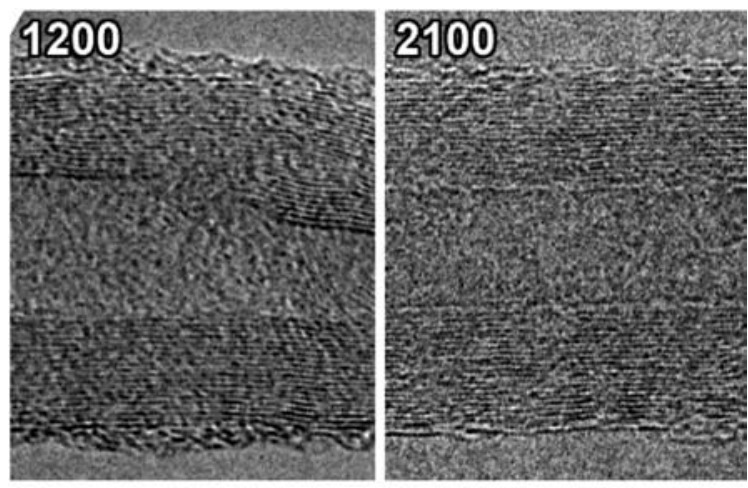

FIGURE 5 (a) Characteristic TEM images of MWCNTs (batch II) annealed at different temperatures (in ${ }^{\circ} \mathrm{C}$ ). (b) Young's modulus $E$ for pristine [7] MWCNTs and annealed at 1200,1700 , 2100 and $2400{ }^{\circ} \mathrm{C}$. Values for the same annealing temperature are shifted for $40^{\circ} \mathrm{C}$ to ease the view
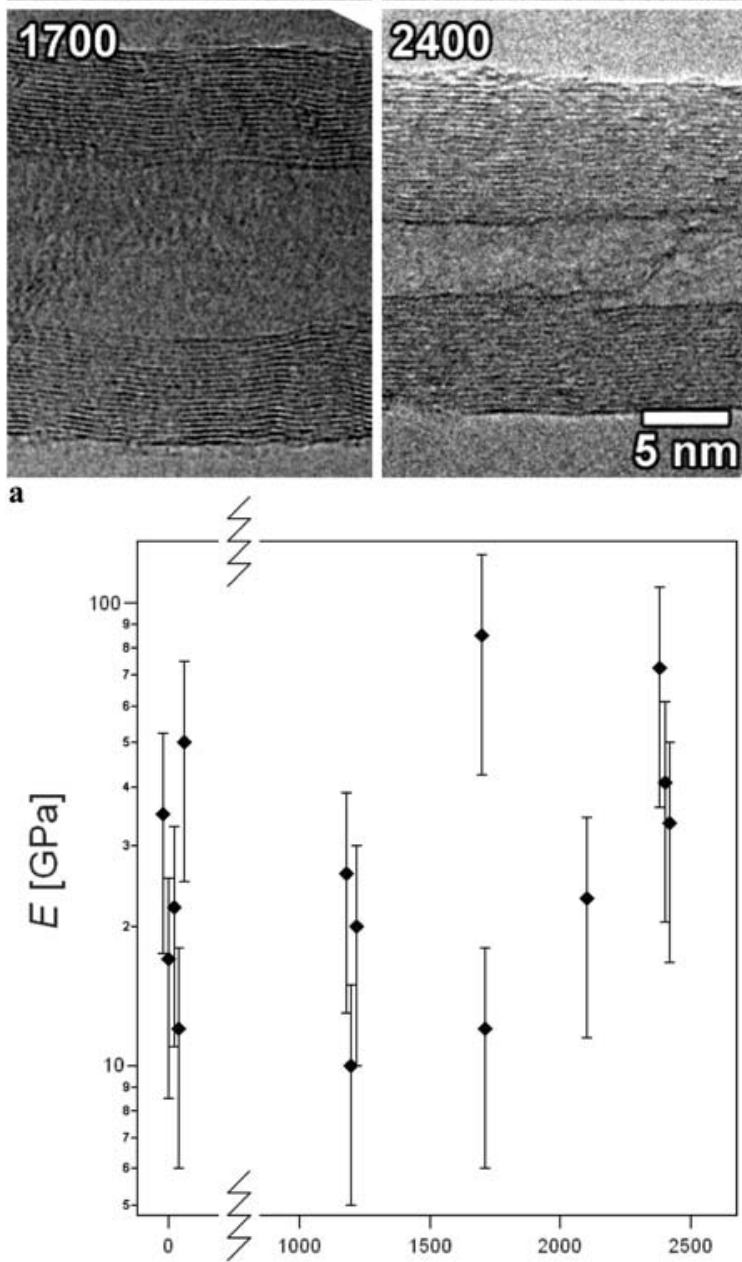

b

annealing temperature $\left[{ }^{\circ} \mathrm{C}\right]$ ity of defects is rather unknown, and more detailed theoretical and experimental studies have to be done in order to estimate the critical density required to lower the Young's modulus of CCVDgrown MWCNTs significantly. Furthermore, one needs to explain the difference between these values and those obtained by theoretical studies [38] and measurements on MWCNTs grown by arc-discharge or laser-ablation methods. The growth mechanism for the tubes produced by these techniques is very different compared to CCVD-grown tubes. In particular, the synthesis temperature reaches more than $3000^{\circ} \mathrm{C}$, in contrast to CCVD where a temperature below $1000^{\circ} \mathrm{C}$ is applied.

Our results suggest that more control is needed in the growth process of MWCNTs produced by CCVD. Possible improvements include cleaner atmosphere in the furnace, well-defined geometry and size of the catalyst particles, as well as suitable orientations between the crystallographic planes of the catalyst particle and the support. Here we used only acetylene; other carbon sources might give different results. Comparative studies where only one production parameter is varied [14] or in situ observations of the MWCNT growth [39] could lead to a better understanding of the growth process.

Since the CCVD method is the most promising in terms of large-scale production, it is imperative to find better production conditions which could make MWCNTs with better structural quality and with higher modulus. At the present stage, they do not give the high reinforcement as expected from CNTs. Alternatively, CCVD-grown singlewalled or double-walled nanotubes should be used for composites, where annealing is more efficient due to the lower initial number of structural defects. the value of $1 \mathrm{TPa}$ and clearly stays crease in modulus between MWCNTs annealed at $1200^{\circ} \mathrm{C}$ and $2400^{\circ} \mathrm{C}$, but for a quantitative analysis more statistics are needed. Since all our measurements give low values for $E$, we conclude that annealing cannot annihilate the defects present in the structure and as a consequence cannot improve the mechanical properties of CCVD-grown MWCNTs.
We have shown that defects

\section{4}

\section{Conclusion}

in the structure of MWCNTs produced by the CCVD method weaken the elastic modulus and they cannot be fully eliminated by high-temperature annealing up to $2400{ }^{\circ} \mathrm{C}$. Furthermore, none of the proposed production recipes give MWCNTs of sufficient mechanical strength, even though apparently they show good structural quality. The dens-
ACKNOWLEDGEMENTS We thank G. Beney (EPFL) for polishing alumina membranes, Prof. J. Brugger (EPFL) for $\mathrm{Si}_{3} \mathrm{~N}_{4} \mathrm{mi}-$ crofabricated membranes, J.-P. Salvetat (CNRS Orléans) for discussions as well as Centre Interdisciplinaire de Microscopie Electronique (CIME) at EPFL for access to electron microscopes and technical support. The study was performed within the TMR network 'Nanocomp' of the European Community and supported in part by the Swiss National Science Foundation and its NCCR 'Nanoscale Science' program. 
A. Fonseca acknowledges the Region of Wallonia (SYNATEC Convention No. 0014526) and K. Hernadi thanks the National Science Foundation of Hungary (OTKA T046491) for financial support.

\section{REFERENCES}

1 S. Iijima: Nature 354, 56 (1991)

2 J.W.G. Wildoer, L.C. Venema, A.G. Rinzler, R.E. Smalley, C. Dekker: Nature 391, 59 (1998)

3 P. Kim, L. Shi, A. Majumdar, P.L. McEuen: Phys. Rev. Lett. 87, 215502 (2001)

4 M.M.J. Treacy, T.W. Ebbesen, J.M. Gibson: Nature 381, 678 (1996)

5 E.W. Wong, P.E. Sheehan, C.M. Lieber: Science 277, 1971 (1997)

6 M.R. Falvo, G.J. Clary, R.M. Taylor, V. Chi, F.P. Brooks, S. Washburn: Nature 389, 582 (1997)

7 J.P. Salvetat, A.J. Kulik, J.M. Bonard, G.A.D. Briggs, T. Stockli, K. Metenier, S. Bonnamy, F. Beguin, N.B. Burnham, L. Forro: Adv. Mater. 11, 161 (1999)

8 P. Poncharal, Z.L. Wang, D. Ugarte, W.A. de Heer: Science 283, 1513 (1999)

9 M.F. Yu, O. Lourie, M.J. Dyer, K. Moloni, T.F. Kelly, R.S. Ruoff: Science 287, 637 (2000)

10 M.F. Yu, B.S. Files, S. Arepalli, R.S. Ruoff: Phys. Rev. Lett. 84, 5552 (2000)

11 M. Jose-Yacaman, M. Miki-Yoshida, L. Rendon, J.G. Santiesteban: Appl. Phys. Lett. 62, 202 (1993)

12 H. Dai: Top. Appl. Phys. 80, 29 (2001)
13 S. Amelinckx, X.B. Zhang, D. Bernaerts, X.F. Zhang, V. Ivanov, J.B. Nagy: Science 265, 635 (1994)

14 T. de los Arcos, M.G. Garnier, P. Oelhafen, D. Mathys, J.W. Seo, C. Domingo, J.V. Garcia-Ramos, S. Sanchez-Cortes: Carbon 42, 187 (2004)

15 K. Hernadi, A. Fonseca, J.B. Nagy, D. Bernaerts, A. Fudala, A.A. Lucas: Zeolites 17, 416 (1996)

16 S. Delpeux, K. Szostak, E. Frackowiak, S. Bonnamy, F. Beguin: J. Nanosci. Nanotechnol. 2, 481 (2002)

17 F. Béguin, S. Delpeux-Ouldriane, K. Szostak: Canadian Patent No. 2374848 (2002); Japanese Patent No. 5941/02 (2002); US Patent No. 10/095 121 (2002)

18 E. Couteau, K. Hernadi, J.W. Seo, L. ThienNga, C. Miko, R. Gaal, L. Forro: Chem. Phys. Lett. 378, 9 (2003)

19 J.P. Cleveland, S. Manne, D. Bocek, P.K. Hansma: Rev. Sci. Instrum. 64, 403 (1993)

20 A. Hamwi, H. Alvergnat, S. Bonnamy, F. Beguin: Carbon 35, 723 (1997)

21 M. Ahlskog, E. Seynaeve, R.J.M. Vullers, C. Van Haesendonck, A. Fonseca, K. Hernadi, J.B. Nagy: Chem. Phys. Lett. 300, 202 (1999)

22 R. Martel, H.R. Shea, P. Avouris: Nature 398, 299 (1999)

23 J.P. Salvetat, G.A.D. Briggs, J.M. Bonard, R.R. Bacsa, A.J. Kulik, T. Stockli, N.A. Burnham, L. Forro: Phys. Rev. Lett. 82, 944 (1999)

24 J.M. Gere, S.P. Timoshenko: Mechanics of Materials (PWS-KENT, Boston 1990)

25 P. Avouris, T. Hertel, R. Martel, T. Schmidt, H.R. Shea, R.E. Walkup: Appl. Surf. Sci. 141, 201 (1999)
26 B.T. Kelly: Physics of Graphite (Applied Science, London 1981)

27 M.C. Payne, M.P. Teter, D.C. Allan, T. Arias, J.D. Joannopoulos: Rev. Mod. Phys. 64, 1045 (1992)

28 J.P. Perdew, K. Burke, M. Ernzerhof: Phys. Rev. Lett. 77, 3865 (1996)

29 M.D. Segall, P.J.D. Lindan, M.J. Probert, C.J. Pickard, P.J. Hasnip, S.J. Clark, M. Payne: J. Phys.: Condens. Matter 14, 2717 (2002)

30 Y. Hirai, S. Nishimaki, H. Mori, Y. Kimoto, S. Akita, Y. Nakayama, Y. Tanaka: Jpn. J. Appl. Phys. 1 42, 4120 (2003)

31 O. Zhou, R.M. Fleming, D.W. Murphy, C.H. Chen, R.C. Haddon, A.P. Ramirez, S.H. Glarum: Science 263, 1744 (1994)

32 C.C. Han, J.T. Lee, H. Chang: Chem. Mater. 13, 4180 (2001)

33 R. Andrews, D. Jacques, D. Qian, E.C. Dickey: Carbon 39, 1681 (2001)

34 D. Bom, R. Anrews, D. Jacques, J. Anthony, B. Chen, M.S. Meier, J.P. Selegue: Nano Lett. 2, 615 (2002)

35 A.A. El-Barbary, R.H. Telling, C.P. Ewels, M.I. Heggie, P.R. Briddon: Phys. Rev. B 68 , 144107 (2003)

36 K. Niwase: Phys. Rev. B 52, 15785 (1995)

37 A. Yasuda, N. Kawase, F. Banhart, W. Mizutani, T. Shimizu, H. Tokumot: J. Phys. Chem. B 106, 1849 (2002)

38 J.P. Lu: Phys. Rev. Lett. 79, 1297 (1997)

39 S. Helveg, C. Lopez-Cartes, J. Sehested, P.L. Hansen, B.S. Clausen, J.R. RostrupNielsen, F. Abild-Pedersen, J.K. Norskov: Nature 427, 426 (2004) 